\title{
ANALISA PERKEMBANGAN JASA TRANSPORTASI BUS ANTAR KOTA DALAM PROPINSI SULAWESI SELATAN DI KOTA PALOPO
}

\author{
SAMSIR, HAEDAR, MUH. YUSUF Q
}

\begin{abstract}
ABSTRAK
Transportasi atau pengangkutan merupakan bidang kegiatan yang sangat penting dalam kehidupan masyarakat indonesia. Pentingnya transportasi bagi masyarakat indonesia di sebabkan oleh beberapa faktor antara lain, keadaan geografis indonesia yang terdiri dari ribuan pulau kecil dan besar, perairan yang terdiri dari sebagian besar laut, sungai dan danau yang memungkinkan pengangkutan dilakukan melalui darat, perairan, dan udara guna menjangkau seluruh wilayah indonesia.

Pelitian ini bertujuan untuk mengetahui dan menganalisis faktor-faktor yang mempengaruhi perkembangan jasa angkutan bus besar antarkota di kota palopo. Analisis terhadap perkembangan jasa angkutan bus besar antar kota di lakukan dengan menggunakan metode penelitian kuantitatif.

Berdasarkan hasil penelitian faktor pendapatan mayarakat mempunyai pengaruh positif terhadap perkembangan jasa angkutan bus besar antar kota di kota palopo yakni sebesar 98,6\% sedangkan 1,4\% di pengaruhi faktor lainnya.

Kesimpulan bahwa Pendapatan penduduk berpengaruh secara signifikan terhadap perkembangan jasa transportasi bus antarkota, di mana semakin meningkat pendapatan penduduk maka permintaan akan jasa transportasi akan meningkat pula seiring dengan kebutuhan masyarakat akan angkutan untuk memenuhi kebutuhan sehari- harinya jumlah penduduk terhadap perkembangan jasa transportasi bus antarkota di kota palopo menunjukan bahwa besarnya nilai $R$-squared sedang yaitu 0,986. Nilai ini berarti bahwa hanya 98,6 \% variable independent dapat di jelaskan oleh model.sehingga di sarankan agar Bagi perusahaan bus atau operator bus agar meningkatkan kualitas pelayanan yang diberikan kepada pengguna jasa angkutan bus.
\end{abstract}

Kata kunci : jasa angkutan Bus Besar Antar Kota, Pendapatan penduduk, jumlah penduduk, peningkatan perekonomian. 


\section{Pendahuluan}

\section{Latar belakang}

Transportasi atau pengangkutan merupakan bidang kegiatan yang sangat penting dalam kehidupan masyarakat indonesia. Pentingnya transportasi bagi masyarakat indonesia di sebabkan oleh beberapa faktor antara lain, keadaan geografis indonesia yang terdiri dari ribuan pulau kecil dan besar, perairan yang terdiri dari sebagian besar laut, sungai dan danau yang memungkinkan pengangkutan dilakukan melalui darat, perairan, dan udara guna menjangkau seluruh wilayah indonesia (muhammad, 1998:7).

Secara umum transportasi memegang peranan penting dalam dua hal yaitu pembangunan ekonomis dan pembangunan non ekonomis. Tujuan yang bersifat ekonomis misalnya peningkatan pendapatan nasional, mengembangkan industri nasional dan menciptakan serta memelihara tingkat kesempatan bagi masyarakat. Sejalan dengan tujuan ekonomis tersebut adapula tujuan yang bersifat non ekonomis yaitu untuk mempertinggi integritas bangsa, serta meningkatkan pertahanan dan keamanan nasional (salim, 2006:2).

Propinsi sulawesi selatan khususnya kota palopo merupakan salah satu kota madya yang cukup srategis dalam upaya pengembangan ekonomi nasional yang perlu di dukung dengan adanya jalur pergerakan secara nasional atau internasional baik melalui transportasi darat, laut maupun udara. hal ini perlu dilakukan guna mempromosikan dan memesarkan potensi andalan yang ada, jaminan investasi yang mantap, serta penyediaan sarana dan prasarana transportasi yang dapat melayani pola pergerakan barang dan/atau orang dengan aman, nyaman dan lancar.

Transportasi darat dilakukan melalui jalan raya memiliki kelebihan dibandingkan jenis angkutan lain, yaitu kemampuannya untuk melayani angkutan dari pintu ke pintu / " door to door ". angkutan darat melalui jalan raya dapat dilihat juga sebagai pemberi umpan atau "feeder" bagi moda trasportasi lainnya dengan kata lain merupakan mata rantai awal dan ahir dari seluruh sistem trasportasi (warpani,1990:31).

Permintaan jasa transportasi baru akan ada, apabila ada faktor - faktor yang mendorongnya . permintaan jasa trasportasi tidak berdiri sendiri , melainkan tersembunyi di balik kepentingan yang lain. Permintaan akan jasa angkutan, baru akan timbul jika ada hal - hal di balik permintaan itu , misalnya untuk rekreasi, keinginan untuk ke sekolah atau untuk berbelanja, keinginan untuk menengok keluarga yang sakit, dan sebagainya (Nasution, 2004:6)

Masalah penelitian ini adalah faktor - faktor apakah yang akan mempengaruhi perkembangan jasa angkutan bus besar antar kota di palopo?. Tujuan penelitian ini adalah (a) Untuk mengetahui dan menganalisis perkembangan jasa transportasi bus antar kota di kota palopo, (b) Untuk 
mengetahui faktor - faktor yang mempengaruhi perkembangan jasa angkutan bus besar antar kota di kota palop

\section{Metode Penelitian}

Lokasi dan waktu penelitian

Kegiatan penelitian ini di lakukan di terminal Dangerakko kota palopo, dimana terdapat bus besar angkutan kota dari semua perusahaan bus besar angkutan antar kota diantaranya: Bus bintang prima, Bus alam indah, Bus bintang timur, Bus pipos, Bus haji beddu solo, Bus, karisma, Bus gunung rejeki, dan Bus litha \& co. Penelitian dilaksanakan selama 60 hari ( 2 bulan ).

Jenis dan sumber data

(a) Data primer yaitu data ini di peroleh dari informan yaitu seseorang yang dianggap mengetahui permasalahan yang sering di kaji dalam penelitian. Penentuan informan di lakukan terhadap beberapa informasi dilakukan terhadap beberapa informan yang memeliki kriteria sebagai berikut : Mereka yang menguasai dan memahami pokok permasalahannya dan Mereka yang sedang terlibat dalam kegiatan penelitian. Berdasarkan hal tersebut yang dapat dijadikan sebagai informan adalah : Staf karyawan perusahaan bus besar sebagai penyedia jasa trasportasi dan petugas yang bertugas pada fasilitas publik pendukung sistem trasportasi/petugas DLLAJ

(b) Data sekunder yaitu data - data (time series) selama 7 tahun (2005 - 20011) yang diperoleh dari: Badan pusat statistik (BPS) kota palopo, kantor dinas perhubungan kota palopo dan perusahaan bus besar antar kota.

Populasi dan sampul

Populasi dalam penelitian ini adalah semua usaha jasa angkutan bus besar antar kota yang ada diterminal Dangerakko. Pemilihan sampel dalam penelitian ini adalah dengan metode total sampling, yakni dengan menggunakan seluruh populasi sebagai sampel.

Metode pengumpulan data

Metode pengumpulan data yang digunakan dalam penelitian ini yaitu: (a) Penelitian lapangan ( field researc); Penelitian dilakukan dengan melakukan pengamatan langsung kelapangan atau obyek penelitian dan memperoleh keterangan dari staf karyawan perusahaan bus besar antar kota, (b) Penelitian kepustakaan (librari research); Studi pustaka dalam penelitian ini dilakukan dengan cara mencari, mencatat, menginvestarisasi, dan mengkaji data sekunder yang telah ada. 


\section{Metode Analisis Data}

Sebagai telah mengemukakan pada bab sebelumnya, masalah yang dibahas dalam penelitian ini adalah faktor-faktor apakah yang dibahas dalam penelitian ini adalah faktor - faktor apakah yang mempengaruhi perkembangan perkembangan jasa angkutan bus besar antara kota di kota palopo? Oleh karna itu, untuk menganalisis variable-variable yang mempengaruhi perkembangan jasa angkutan bus besar antar kota di palopo digunakan metode regresi berganda (multiple regression). Bentuk umum model yang akan digunakan adalah:

\section{$\mathrm{Y}=\mathrm{b} 0+\mathrm{b} 1 \mathrm{x} 1+\mathrm{b} 2 \times 2+\ldots .$.}

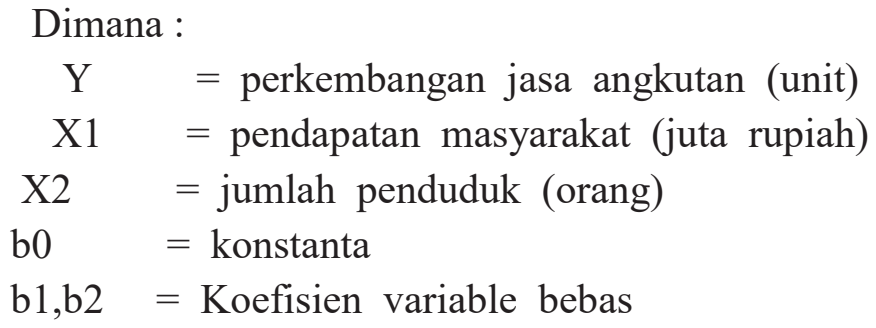

Sedangkan untuk mengetahui tingkat signifikansi dari masing-masing koefisien regresi variable independent terhadap variable dependen maka dapat menggunakan uji statistik diantaranya :

Analisis koefisien determinasi $\left(R^{2}\right)$

Untuk mengetahui besarnya pengaruh variable independen yaitu pendapatan penduduk (X1), dan jumlah penduduk (X2), terhadap variable dependen dalam hal ini perkembangan jasa transportasi bus antar kota (Y) maka digunakan analisis koefisien determinasi $\left(R^{2}\right)$. Koefisien determinasi $\left(R^{2}\right)$ yang kecil atau mendekati nol berarti kemampuan variable-variable independen dalam menjelaskan variasi variable dependen amat terbatas. Nilai $R^{2}$ yang mendekati satu berarti variable-variable independen memberikan hampir semua informasi yang di butuhkan untuk memprediksi variable-variable dependen.

\section{Hasil Penelitian Dan Pembahasan}

Deskripsi hasil penelitian

Sejarah singkat lokasi penelitian

Kota palopo , dahulu disebut kota Administrtip (kotip) palopo, merupakan ibu kota kabupaten luwu yang dibentuk berdasarkan peraturan pemerintah (PP) Nomor tahun 42 tahun 1986. Seiring dengan perkembangan saman, tatkala gaung reformasi bergulir dan melahirkan UU No. 22 tahun 1999 dan pp 129 tahun 2000, telah membuka peluang bagi kota Administratip 
di seluruh indonesia yang telah memenuhi sejumlah persyaratan untuk dapat ditingkatkan statusnya menjadi sebuah daerah otonom.

Ide peningkatan status kotip palopo menjadi daerah otonom, bergulir mulai aspirasi masyarakat yang menginginkan peningkatan status kala itu, yang ditandai dengan lahirnya beberapa dukungan peningkatan status kotip palopo menjadi Daerah otonom kota palopo dari berbagai unsur kelembagaan penguat seperti :

a. Surat Bupati luwu No. 135/TAPEM Tanggal 9 Januari 2001, tentang Usul peningkatan status kotip palopo menjadi kota palopo

b. Keputusan DPRD kabupaten luwu No. 55 tahun 2000 tanggal 7 september 2000, tentang persetujuan pemekaran/peningkatan status kotip palopo menjadi kota otonomi.

c. Surat Gubernur propinsi sulawesi selatan No. 135/922/OTODA tanggal 30 maret 2001 Tentang usul pembentukan kotip palopo menjadi kota palopo.

d. Keputusan DPRD Propinsi sulawesi selatan No. 41/111/2001 tanggal 29 maret 2001 Tentang persetujuan pembentukan kotip palopo menjadi kota palopo Hasil seminar kota administratip palopo menjadi kota palopo. Surat dan dukungan Organisasi masyarakat, organisasi politik, organisasi pemuda, organisasi wanita dan profesi. Pula di barengi oleh aksi bersama LSM dari kabupaten luwu memperjuangkan kotip palopo menjadi kota palopo, kemudian dilanjutkan oleh forum peduli kota.

Akhirnya, setelah pemerintah puat melalui depdagri meninjau kelengkapan administrasi serta melihat sisi potensi, kondisi wilayah dan letak geograpis kotip palopo yang pada jalur Trans sulawesi dan sebagai pusat pelayanan jasa perdagangan terhadap beberapa kabupaten yang meliputi kabupaten luwu, luwu utara, Tana Toraja, kabupaten wajo serta didukung dengan sarana dan prasarana yang memadai, kotip palopo kemudian ditingkatkan statusnya menjadi daerah otonom kota palopo.

Tanggal 2 juli 2002, merupakan salah satu tonggak sejarah perjuangan pembangunan kota palopo, dengan ditanda tanganinya prasasti pengakuan atas daerah otonom kota kota palopo oleh bapak mentri dalam Negri Republik Indonesia, berdasarkan UU No. 11 tahun 2002 tentang pembentukan daerah otonom kota palopo kabupaten mamasa propinsi sulawesi selatan, yang ahirnya menjadi sebuah daerah otonom dengan bentuk dan model pemerintah dan serta letak wilayah geograpis tersendiri, berpisah dari induknya yakni kabupaten luwu.

Diawal terbentuknya sebagai daerah otonom, kota palopo hanya memiliki 4 wilayah kecamatan yang meliputi 19 keluruhan dan 19 desa. Namun seiring dengan perkembangan dinamika kota palopo dalam segala bidang sehingga untuk mendekatkan pelayanan pemerintah kepada masyarakat, 
maka pada tahun 2006 wilayah kecamatan di kota palopo kemudian dimekarkan menjadi 9 kecamatan dan 48 kelurahan.

Kota palopo dinahkodai pertama kali oleh Bapak Drs. H.P.A. Tendriadjeng, Msi, yang diberi amanah sebagai pejabat Walikota (caretaker) kala itu mengawali pembangunan kota palopo selama kurun waktu satu tahun, hingga kemudian dipilih sebagai walikota defenitif oleh dewan perwakilan rakyat daerah kota palopo untuk memimpin kota palopo periode 2003-2008, yang sekaligus mencatatkan dirinya selaku Walikota pertama di kota palopo.

Analisis Dan pembahasan

Jumlah penduduk kota palopo

Penduduk adalah semua orang yang berdomisili diwilayah geografis suatu wilayah selama enam bulan atau lebih dan atau mereka yang berdomisili kurang dari enam bulan tetapi bertujuan menetap. Pertumbuhan penduduk di akibatkan oleh tiga komponen yaitu : fertilitas, mortalitas, dan migrasi. Tingginya laju pertumbuhan penduduk di beberapa bagian di dunia ini menyebabkan jumlah penduduk meningkat dengan cepat.

Jumlah penduduk adalah semua orang yang menetap di suatu wilayah tertentu dalam jangka waktu tertentu. Jumlah penduduk suatu negara dapat di ketahui melalui beberapa cara yaitu sensus penduduk, survey penduduk, dan registrasi penduduk.

Sensus penduduk (cacah jiwa) yaitu penghitungan jumlah penduduk oleh pemerintah dalam jangka waktu tertentu secara serentak. Sensus penduduk dilaksanakan tiap 10 tahun dan dilaksanakan oleh Badan pusat statistik (BPS).

Survey penduduk yaitu kegiatan yang di lakukan oleh pemerintah untuk melakukan penelitian dan menyediakan data statistik kependudukan pada waktu dan tempat tertentu. Survey yang di lakukan meliputi survey ekonomi nasional, survey angkatan kerja nasional, dan survey penduduk antar sensus (SUPAS).

Registrasi penduduk yaitu proses kegiatan pemerintah yang meliputi pencatatan kelahiran, kematian, perkawinan, perceraian, perubahan tempat tinggal, dan perubahan pekerjaan secara rutin. Pencatatan ini terutama dilakukan ditingkat pemerintah terendah yaitu kelurahan.

Perkembangan tingkat pendapatan penduduk kota palopo

Salah satu indikator untuk menilai keberhasilan pembangunan suatu daerah adalah dengan melihat tingkat pertumbuhan ekonominya. Pertumbuhan ekonomi diharapkan mampu meningkatkan kemampuan faktor-faktor produksiyang merangsang bagi berkembangnya ekonomi daerah dalam skala yang lebih besar. Searah kebijaksanaan pemerintah setelah mulai di terapkan otonomi daerah sejak tahun 2001, di harapkan pembangunan di daerah dapat lebih mendorong pemerataan pembangunan dan juga mempercepat pertumbuhan 
ekonomi suatu daerah. Pertumbuhan ekonomi yang stabil akan berdampak pada semakin meningkatnya pendapatan penduduk yang pada ahirnya bertujuan meningkatkan kesejahteraan masyarakat.

Kondisi perekonomian kota palopo dapat dilihat pada usahanya meningkatkan laju perputaran roda perekonomian, pemerintah kota palopo terus menerus berusaha mengembangkan dan memberdayakan segala potensi yang di milikinya dengan membuat kebijaksanaan serta langkah-langkah strategis yang kemudian di aktulisasikan dalam bentuk pembangunan selama ini di laksanakan. Peningkatan yang terjadi pada jasa angkutan antarkota dalam suatu daerah dapat di lihat pada kemajuan perekonomian nilai perubahan produk domestik regional Bruto (PDRB) yang terjadi pada daerah tersebut. Produk Domestik Regional Bruto merupakan nilai dari seluruh barang dan jasa yang di produksi dalam satu tahun di wilayah tertentu tanpa membedakan kepemilikan faktor-faktor produksi yang di gunakan dalam proses produksi itu.

Data pendapatan Domestik Regional Bruto (PDRB) merupakan data dasar dan utama dalam kerangka perencanaan pembangunan di daerah, di samping sebagai informasi tentang kondisi dan perekonomian makro regional. Oleh karna itu data PDRB pada dasarnya tidak hanya bermanfaat bagi kepentingan teknis perencanaan pembangunan, tetapi juga dapat menjadi bahan untuk menentukan kebijakan baik bagi para pelaku pembangunan maupun untuk segenap pelaku ekonomi.

Dalam upaya meningkatkan pertumbuhan ekonomi di kota palopo di mana kondisi perekonomian daerah tersebut sangat tergantung pada potensi dan sumber daya yang dimiliki, berbagai kebijaksanaan serta upaya yang telah di lakukan oleh pemerintah khususnya pemerintah kota palopo. Untuk mengetahui pertumbuhan suatu daerah maka perlu di cermati nilai dan pertumbuhan PDRB.

Produk Domestik Regional Bruto (PDRB) terbagi atas dua yaitu PDRB berdasarkan harga konstan dan PDRB harga yang berlaku. Namu, dengan adanya perubahan harga dari tahun ke tahun yang menyebabkan PDRB berdasarkan harga berlakujuga turut berubah-ubah setiap tahun

\section{Penutup}

Kesimpulan penelitian ini adalah: (a) Pendapatan penduduk berpengaruh secara signifikan terhadap perkembangan jasa transportasi bus antarkota, di mana semakin meningkat pendapatan penduduk maka permintaan akan jasa transportasi akan meningkat pula seiring dengan kebutuhan masyarakat akan angkutan untuk memenuhi kebutuhan sehari- harinya. (b) Jumlah penduduk yang semakin meningkat dapat mendorong perkembangan jasa transportasi bus antar kota. Jumlah penduduk yang semakin meningkat membuktikan bahwa di kota 
palopo masih banyak penduduk yang membutuhkan jasa angkutan untuk melakukan kegiatan sehari-hari. Meskipun pengaruhnya tidak signifikan. (c) Jumlah penduduk terhadap perkembangan jasa transportasi bus antarkota di kota palopo menunjukan bahwa besarnya nilai $R$-squared sedang yaitu 0,986 . Nilai ini berarti bahwa hanya 98,6 \% variable independent dapat di jelaskan oleh model. (d) Uji F-statistik (144,382) menunjukan bahwa semua variable independent dalam model Regresi yaitu pendapatan penduduk dan jumlah penduduk berpengaruh secara bersama-sama mempengaruhi variable perkembangan jasa transportasi bus antarkota di kota palopo dengan tingkat signifikansi 0,000. Adapun saran penelitian ini adalah : (a) Dalam upaya meningkatkan laju roda perekonomian di kota palopo, maka diharapkan agar sarana transportasi darat terutama jasa angkutan bus besar antarkota dapat lebih di kembangkan, bukan hanya pada jumlah armadanya tetapi perusahaan bus atau operator bus juga. (b) Bagi perusahaan bus atau operator bus agar meningkatkan kualitas pelayanan yang diberikan kepada pengguna jasa angkutan bus. (c) Dan ahirnya penulis berharap kepada pemerintah kota palopo agar memberi kemudahan bagi para investor untuk menanamkan modal melalui usaha angkutan antar kota sebagai salah satu upaya untuk meningkatkan perekonomian.

\section{Daftar Pustaka}

Abdul Kadir Muhammad. 1998. Hukum pengangkutan Niaga. Bandung. Citra Aditya Bakti.

Ahmad munawar. 2005. Dasar-Dasar Teknik Transportasi. Jogjakarta. Betta Ofset.

Ananonim. 2008. Badan pusat statistik kota palopo dalam angka 2007. Palopo.

Ananonim. 2008. Badan pusat statistik penduduk dan tenaga kerja. Jakarta.

Damodar Gujarati. 1995. Ekonomitrika Dasar. Jakarta. Erlangga (AK. Sumarno Zain).

Morlok Edward K. 1995 Pengantar teknik dan perencanaan Transportasi. Jakarta. Erlangga.

Mudrajad Kuncoro. 2003. Metode Riset untuk bisnis dan Ekonomi. Jakarta. Penerbit Erlangga.

Nasution M Nur. 2004. Manajemen Transportasi. Jakarta Ghalia indonesia. 
Ofyar Z Tamin. 1997. Perencanaan dan Pemodelan Transportasi. Bandung. Penerbit ITB .

Raga Paulus MT . 2004. Kajian Kinerja Pelayanan Transportasi. (Warta Penelitian Perhubungan No. 01/THN. XVI/2004. Jakarta . Tidak dipublikasikan).

Riyanto Raina Dwi. 2002. Segmentasi Pasar dan Elastisitas Permintaan Angkutan Umum (Study Kasus Bus Perkotaan Yogyakarta). (Tesis S2 Transportasi UGM, tidak dipublikasikan).

Salim Abbas. 1997. Manajemen Transportasi. Jakarta. PT. Raja Grafindo Persada.

Sugiarto, Tedy Herlambang, Brastoro, Rahmat sudjana dan Said Kelana, 2002, Ekonomi Mikro : Sebuah Kajian Komprehensif. Jakarta. Penerbit PT. Gramedia Pustaka Utama.

Suwardjoko Warpani. 1990. Merencanakan Sistem Pengangkutan, Bandung. ITB

Usman dan Akbar. 1995. Metodologi penelitian Sosial. Jakarta. PT. Bumi Aksara.

Yafiz M. 2002. Analisis Kinerja Jasa Transportasi Angkutan Kota di kota Pekanbaru. Program PascaSarjana /S3 , Institut pertanian Bogor. (http: //rudyct.tripod.com/sem1_023/m_yafizhtm), diakses 12 desember 2011. 